\title{
COMMENTARY
}

\section{Oral care and pulmonary infection - the importance of plaque scoring}

\author{
Matt P Wise ${ }^{1 *}$ and David W Williams ${ }^{2}$ \\ See related research by Gu et al., http://ccforum.com/content/16/5/R190
}

\begin{abstract}
Improving the quality of oral hygiene is recognised as an important counter measure for reducing the incidence of ventilator-associated pneumonia amongst critically ill patients. Toothbrushing physically disrupts the dental plaque that acts as a reservoir for pulmonary infection and therefore has the potential to reduce the incidence of ventilator-associated pneumonia. Gu and colleagues performed a systematic review and meta-analysis of oral hygiene with and without a toothbrush and found no difference in the incidence of pneumonia in mechanically ventilated patients. The diagnosis of ventilator-associated pneumonia is prone to bias and future studies of oral care interventions should focus on measures of oral cleanliness such as plaque and gingival scores. Once the optimal strategy for oral hygiene is defined in the critically ill, larger studies focussing on ventilator-associated pneumonia or mortality can be conducted.
\end{abstract}

In the previous issue of Critical Care, Gu and colleagues [1] report the results of a systematic review and metaanalysis of oral hygiene with and without a toothbrush on ventilator-associated pneumonia (VAP). Over the past two decades an increasing body of data has demonstrated that poor oral hygiene increases the incidence of pneumonia in community, residential, hospitalised and critically ill individuals [2]. Dental plaque serves as a reservoir for microorganisms associated with pulmonary infection and these potential respiratory pathogens have been shown to rapidly colonise plaque in mechanically ventilated critically ill patients $[3,4]$. Attention to oral hygiene is recognised as an important component of care, which reduces VAP; however, there is substantial

*Correspondence: mattwise@doctors.org.uk

'Adult Critical Care, University Hospital of Wales, Cardiff, CF14 4XW, UK Full list of author information is available at the end of the article variability in how this is performed [5,6]. Decolonisation strategies with oral antiseptics such as chlorhexidine or topical antibiotics decrease VAP and are included in the European care bundle for prevention of VAP $[7,8]$. Provision of oral hygiene may include any combination of foam swabs, manual or electric toothbrushes, moisturisers, toothpaste, topical antibiotics, and oral antiseptics. However, it is unclear which elements or combinations are most effective at improving oral cleanliness.

Healthy individuals and self-caring patients normally clean their oral cavity with the use of a toothbrush as dental plaque, an archetypal biofilm, can only effectively be removed by mechanical disruption. Healthcare professionals have made the assumption that this would also represent the most effective measure for controlling plaque in mechanically ventilated patients, thereby reducing the burden of respiratory pathogens that could cause VAP. Gu and colleagues [1] explored the data supporting this assumption by undertaking a systematic review and meta-analysis of oral hygiene with and without a toothbrush on VAP. Four randomised clinical trials with 828 patients were identified that met the inclusion criteria. In this analysis, toothbrushing did not reduce the incidence of VAP, critical care mortality or length of stay, antibiotic administration or mechanical ventilationfree days. $\mathrm{Gu}$ and colleagues suggest that these results be cautiously interpreted and that well-designed large randomised clinical trials are urgently required to adequately address this matter. The question remains why a method that effectively disrupts plaque subsequently fails to demonstrate any benefit in this patient population?

VAP is a common infection in critical care and leads to increased mortality, length of stay and cost. The magnitude of attributable mortality is controversial, with recent estimates of 5 to $10 \%$ much lower than historical values. Establishing a diagnosis of VAP in a mechanically ventilated patient is far more complex than it is for an individual presenting with community-acquired pneumonia and agreement amongst clinicians is poor $[9,10]$. It is perhaps not surprising that the small number of studies in the current meta-analysis, which used VAP as the primary outcome measure, failed to show a reduction 
when toothbrushing was used. A more robust outcome measure for studies that aim to improve oral hygiene by disrupting dental plaque would be to measure plaque (and gingival) scores in patients. Unless a reduction in plaque scores can be demonstrated by the intervention under investigation one could not, on the basis of biological plausibility, anticipate any effect on VAP rates. Unfortunately, unlike the dental literature where plaque and gingival scoring is commonplace, this is rarely performed in critically ill patients. This is most likely because plaque scoring necessitates a degree of expertise not present in many critical care healthcare workers and requires a calibration exercise if more than one scorer is used. Most observational studies, including a recent report by Needleman and colleagues, that record plaque scores throughout the period of intubation demonstrate an increase over time $[4,11]$. In the four studies included in the meta-analysis, none measured plaque scores as an outcome measure of toothbrushing. It is therefore difficult to know if the failure of toothbrushing to reduce VAP in these studies was due to this procedure not being performed adequately (no reduction in plaque scores) or plaque removal itself does not alter the incidence of VAP. In contrast, one study reviewed by $\mathrm{Gu}$ and colleagues, which was excluded from the meta-analysis because it did not measure VAP, compared the use of an electric toothbrush with a foam swab for removal of plaque and potential respiratory pathogens [12]. Both interventions were undertaken four times a day and all patients received $0.2 \%$ chlorhexidine at the same time. The use of an electric toothbrush significantly reduced plaque scores compared to the foam swab at day 5. There was also a significant reduction in the mean counts of viable bacteria with the powered toothbrush. It is worth noting that in this study, and despite the toothbrush being a more effective measure of plaque removal, use of the foam swab was also associated with a significant reduction in plaque by day 5 .

The optimal package of care for improving oral hygiene in the critically ill has not been adequately defined and some elements may be counterproductive. Sodium lauryl sulphate is used as a foaming agent in toothpaste but forms inactive low solubility salts with chlorhexidine [13]. Toothpaste must be thoroughly removed prior to chlorhexidine use to prevent inactivation, or a nonfoaming toothpaste used instead. Chlorhexidine may be a less effective antiseptic in vitro than other agents such as essential oils or triclosan-based products but is efficacious in vivo because of a property called substantivity. The drug binds to clean oral surfaces and is then released over time mediating its antimicrobial effect. Chlorhexidine thus works largely by inhibiting the re-accumulation of dental plaque [14] following mechanical cleaning. Lorente and colleagues performed a single centre randomised clinical trial involving treatment with $0.12 \%$ chlorhexidine with manual toothbrushing and standard care [15]. In total, 436 patients were enrolled in the study representing more than half of those included in the meta-analysis. No significant difference was observed between groups in the incidence of the primary outcome measure VAP. Efficacy of the interventions on oral cleanliness was not measured. Importantly, toothbrushing was performed after the administration of chlorhexidine in this study, making this a less effective therapy than if the antiseptic had followed brushing. Considerable choice also exists in the components of mouth care that are available. Thus, chlorhexidine may be used in concentrations from $0.12 \%$ to $2 \%$ and comes as a solution, gel or paste. Alternative antiseptics frequently used in dentistry, such as essential oils or triclosan formulations, might provide more effective plaque control. Toothbrushes may be manual or electric and come with brushes of different sizes or bristle hardness, all of which may influence plaque disruption.

Improving oral hygiene represents one of a number of interventions that may influence the development of VAP [8]. Ideally, further studies exploring the optimal package of care for improving oral cleanliness should be undertaken before planning larger more expensive trials that have outcome measures such as VAP, mortality or length of stay. Powering studies for unambiguous endpoints such as mortality are preferable to those prone to bias, such as VAP, but require far larger numbers of patients. Defining what represents optimal oral care requires a greater understanding of the pathophysiology of the oral cavity, dental plaque, biofilm biology and the oral microbiome, and is dependent on effective collaboration between clinicians from critical care and dentistry.

\section{Abbreviations}

VAP, ventilator-associated pneumonia.

\section{Competing interests}

MPW has received oral care products for research purposes from SAGE Products. MPW has sat on an advisory board for Bard and Merck and has received grant support from NISCHR. He received royalties from WileyBlackwell Publishing, and has received travel accommodations from ISICEM Brussels, British Thoracic Society and Eli Lilly. He has a loan of ElT equipment from CareFusion. DWW has previously received research support relating to oral and respiratory care from SAGE, GlaxoSmithKline, Oraldent, Covidien, and Philips Sonicare.

\section{Acknowledgement}

Marc J Bonten, Professor of molecular epidemiology of infectious diseases, University Medical Centre, Utrecht, Netherlands, for critical reading of the manuscript.

Authors' contributions

MPW and DWW contributed equally to the drafting of the manuscript.

\section{Author details}

${ }^{1}$ Adult Critical Care, University Hospital of Wales, Cardiff, CF14 4XW, UK. ${ }^{2}$ School of Dentistry, Cardiff University, Cardiff, CF14 4XY, UK. 
Published: 10 January 2013

\section{References}

1. Gu WJ, Gong YZ, Pan L, Ni YX, Liu JC: Impact of oral care with versus without toothbrushing on the prevention of ventilator-associated pneumonia: a systematic review and meta-analysis of randomized controlled trials. Crit Care 2012, 16:R190.

2. Wise MP, Williams DW: Oral biofilms, systemic disease, and pneumonia. In Annual Update in Intensive Care and Emergency Medicine 2012. Edited by Vincent J-L. Springer Verlag; 2012:278-288.

3. Scannapieco FA, Stewart EM, Mylotte JM: Colonization of dental plaque by respiratory pathogens in medical intensive care patients. Crit Care Med 1992, 20:740-745

4. Fourrier F, Duvivier B, Boutigny H, Roussel-Delvallez M, Chopin C: Colonization of dental plaque: a source of nosocomial infections in intensive care unit patients. Crit Care Med 1998, 26:301-308.

5. Binkley C, Furr LA, Carrico R, McCurren C: Survey of oral care practices in US intensive care units. Am J Infect Control 2004, 32:161-169.

6. Rello J, Koulenti D, Blot S, Sierra R, Diaz E, De Waele JJ, Macor A, Agbaht K, Rodriguez A: Oral care practices in intensive care units: a survey of 59 European ICUs. Intensive Care Med 2007, 33:1066-1070.

7. Chan EY, Ruest A, Meade MO, Cook DJ: Oral decontamination for prevention of pneumonia in mechanically ventilated adults: systematic review and meta-analysis. BMJ 2007, 334:889

8. Rello J, Lode H, Cornaglia G, Masterton R; VAP Care Bundle Contributors: A European care bundle for prevention of ventilator-associated pneumonia. Intensive Care Med 2010, 36:773-780.

9. Klompas M: Does this patient have ventilator-associated pneumonia? JAMA 2007, 297:1583-1593.
10. Klompas M: Interobserver variability in ventilator-associated pneumonia surveillance. Am J Infect Control 2010, 38:237-239.

11. Needleman I, Hyun-Ryu J, Brealey D, Sachdev M, Moskal-Fitzpatrick D, Bercades G, Nagle J, Lewis K, Agudo E, Petrie A, Suvan J, Donos N, Singer M: The impact of hospitalization on dental plaque accumulation: an observational study. J Clin Periodonto/ 2012, 39:1011-1006.

12. Needleman IG, Hirsch NP, Leemans M, Moles DR, Wilson M, Ready DR, Ismail S, Ciric L, Shaw MJ, Smith M, Garner A, Wilson S: Randomized controlled trial of toothbrushing to reduce ventilator-associated pneumonia pathogens and dental plaque in a critical care unit. J Clin Periodontol 2011, 38:246-252.

13. Barkvoll P, Rølla G, Svendsen K: Interaction between chlorhexidine digluconate and sodium lauryl sulfate in vivo. J Clin Periodontol 1989, 16:593-595.

14. Zanatta FB, Antoniazzi RP, Rösing CK: The effect of $0.12 \%$ chlorhexidine gluconate rinsing on previously plaque-free and plaque-covered surfaces: a randomized, controlled clinical trial. J Periodonto/ 2007, 78:2127-2134.

15. Lorente L, Lecuona M, Jiménez A, Palmero S, Pastor E, Lafuente N, Ramos MJ, Mora ML, Sierra A: Ventilator-associated pneumonia with or without toothbrushing: a randomized controlled trial. Eur J Clin Microbiol Infect Dis 2012, 31:2621-2629.

doi:10.1186/cc11896

Cite this article as: Wise MP, Williams DW: Oral care and pulmonary infection - the importance of plaque scoring. Critical Care 2013, 17:101. 